\title{
Intra-abdominal actinomycosis, the great mime: case report and literature review
}

\author{
*Correspondence: giulia.montori@gmail.com

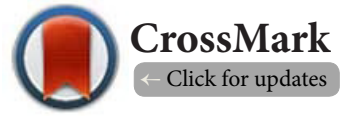 \\ 'Unit of General and Emergency Surgery, Papa Giovanni XXIII Hospital, Bergamo, Italy. \\ ${ }^{2}$ Department of General Surgery III, Ospedale Civile, Brescia University Hospital, Brescia, Italy. \\ ${ }^{3}$ Department of Infectious Diseases, Ospedale Papa Giovanni XIII, Bergamo, Italy. \\ ${ }^{4}$ Department of Anatomopathology, Ospedale Papa Giovanni XIII, Bergamo, Italy.
}

Giulia Montori1 ${ }^{1 *}$, Andrea Allegri', Giulia Merigo', Palamara Fabrizio', Elia Poiasina', Federico Coccolini', Roberto Manfredi', Dario Piazzalunga' ${ }^{1}$, Alessandra Tebaldi ${ }^{3}$, Francesco Filippin ${ }^{4}$, Andrea Gianatti ${ }^{4}$, Luca Baiocchi ${ }^{2}$, Nazario Portolani ${ }^{2}$ and Luca Ansaloni ${ }^{1}$

\begin{abstract}
Background: Actinomycosis is a rare, insidious, infectious disease. Cervicofacial, thoracic and abdominopelvic districts are most commonly involved. Its tendency to involve surrounding structures may mimic a tumor on imaging studies. Early diagnosis, obtained with mini-invasive methods or surgical biopsy, is fundamental to optimize therapeutic approach and to reduce morbidity due to aggressive surgery. Antibiotic therapy is the cornerstone of the treatment of actinomycosis, but the combination with a surgical resection can be necessary in patients who do not respond to medical treatment.

Methods: A 66-years old female presented at our attention with an abdominal, retroperitoneal mass found during clinical tests for a vertiginous syndrome. Patient presented with asthenia, anorexia, weight loss, and sacral pain. A retroperitoneal mass, studied with Computed tomography (CT) and Positron emission tomography (PET), was found. No inflammatory signs were found in laboratory tests. Previous core biopsies did not provide the expected results. Cause of that, the patient was prepared for a surgical laparoscopic biopsy and ureteral stenting. After frozen biopsies, histological findings have identified filaments of Actinomyces. No apparent cause of this infection has been identified at first exploration.

Results: The patient was treated with antibiotic therapy for three months (Amoxicillin: $1 \mathrm{~g}$ three times daily). At three months first follow-up, the CT shows the reduction of the retroperitoneal mass and the presence of diverticulosis of the sigma near the mass, in absence of signs of fistulisation.

Conclusion: Abdominopelvic actinomycosis should be considered in patients with unusual abdominal mass on abdominal CT or PET. Early diagnosis is necessary to avoid aggressive surgery and its morbidities. Open/laparoscopic surgical biopsy is often necessary to identify the infection. Antibiotic therapy is the standard treatment but surgery can help to optimize medical approach removing necrotic tissue and persistent sinuses.
\end{abstract}

Keywords: Actinomycosis, intra-abdominal infection, actinomyces, antimicrobial, antibiotic

\section{Introduction}

Actinomycosis is a chronic progressive suppurative disease characterized by the formation of multiple abscesses, draining sinuses, abundant granulation and dense fibrous tissue. This infection is considered caused by Actinomyces organisms, which are gram-positive anaerobic bacteria; these organisms are considered as opportunistic pathogens, as they are normally present in healthy individuals $[\mathbf{1 , 2}]$. Abdomen is the third body site for the infection of actinomycosis (is involved in 20\%) and when an abdominal mass presents as the clinical symptoms, the local lesion needs to be differentiated from abdominal malignant neoplasia $[3,4]$. We report a case of actinomycosis intra-abdominal infection caused by a misunderstood diverticular disease.

\section{Case presentation}

A 66-year-old woman in apparently good health was admitted to our department for a retroperitoneal mass suspected for malignant. The patient was assessed by oncologists for asthenia, weight loss (more than $14 \mathrm{~kg}$ in two months), and 
sacral pain. The woman had no significant past medical history (appendectomy 14 years ago, inguinal hernia repair, and arterial hypertension), and no use of an intra-uterine device (IUD). At the admission, the clinical examination was negative; in particular abdomen appeared normal without signs of tenderness and no palpable or painful mass. Laboratory investigations revealed white cells count of $11.4 \times 10.000 /$ $\mathrm{mcl}$ with mild neutrophilia, anaemia with hemoglobin of $9.8 \mathrm{~g} / \mathrm{dl}$. Protein-C reactive levels were normal. Other laboratory tests including hepatic function, coagulation, renal and bone profiles, amylase, lipase, lactate dehydrogenase (LDH), carcino-embryonic antigen (CEA), cancer antigen 15.3 (CA 15.3), carcinoma antigen 125 (CA 125) and cancer antigen 19-9 (CA 19-9) were within normal range.

Before coming at our attention, a first thoraco-abdominal CT was performed. The $\mathrm{CT}$ images showing small nodular lesions on the pulmonary parenchyma less than $7 \mathrm{~mm}$ and a left lumbar pathological tissue of $5,7 \mathrm{~cm}$ in the retroperitoneum surrounded the abdominal aorta, common left iliac artery and the omolateral ureter with retrodilatation of urinary tract (Figure 1). The small bowel appeared to be infiltrated like the left ileopsoas muscles. PET shows uptake in the low abdominal region. On these findings, the patient has undergone to ultra-sound (US) and CT-guides biopsies of the abdominal mass. No clearly neoplastic response had come from the fine needle aspiration (FNA): a fibrous tissue with acute and chronic inflammation with eosinophilia and histiocytes cells was found.

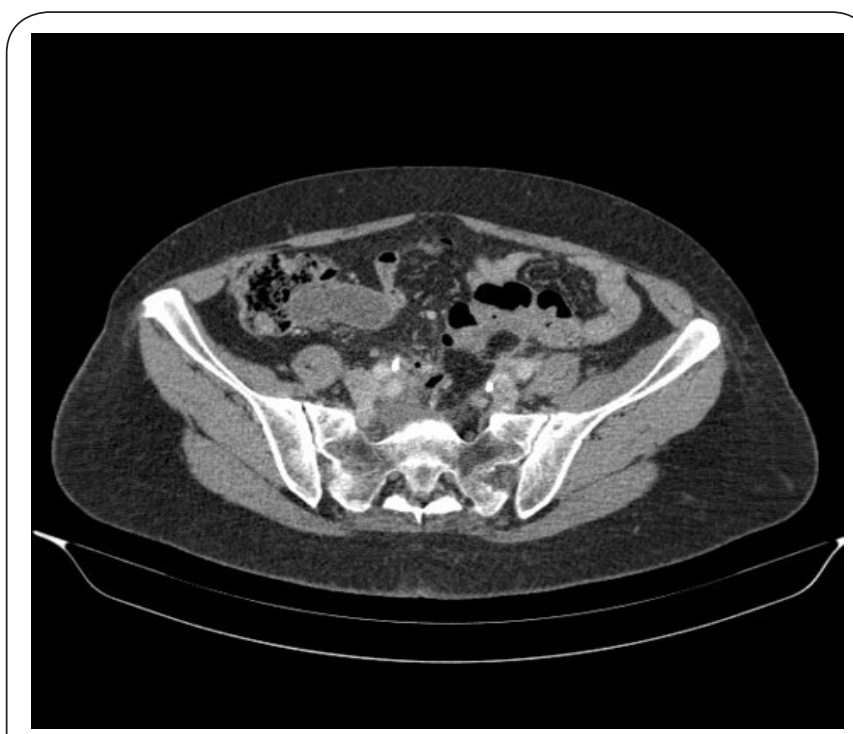

Figure 1. CT scan with big collection indicated in the scan image showing "The pelvic mass in the first CT scan".

At 1 month follow-up CT scan was performed. At the imaging appears the mass enlarged and was closely adherent to the sigma, with a progressive bilaterally dilatation of the urinary tract. An incomplete colonoscopy demonstrated a thick stenosis of the sigma with normal mucosa like ab-estrinseco compression that prevents the passage of the endoscope.

In consideration of the diagnostic images, even though the inconclusive histological response, an exploratory laparoscopy was performed to reach diagnostic biopsies of the mass. Bilateral ureteral stenting was performed at pre-operative time. At the surgical exploration, the mass appeared voluminous and composed by grayish and yellowish granular retroperitoneal tissue, retracting the left colon and proximal sigmoid mesentery, without grossly signs of infiltration (Figure 2). No secondary lesions were visible in the peritoneal cavity. The intraoperative histological examination was not conclusive for malignancy. Surprisingly, culture of material obtained during surgical biopsy yielded Actinomyces, and, at definitive histopathological examination, the diagnosis of retroperitoneal actinomycosis was established (Figure 3).

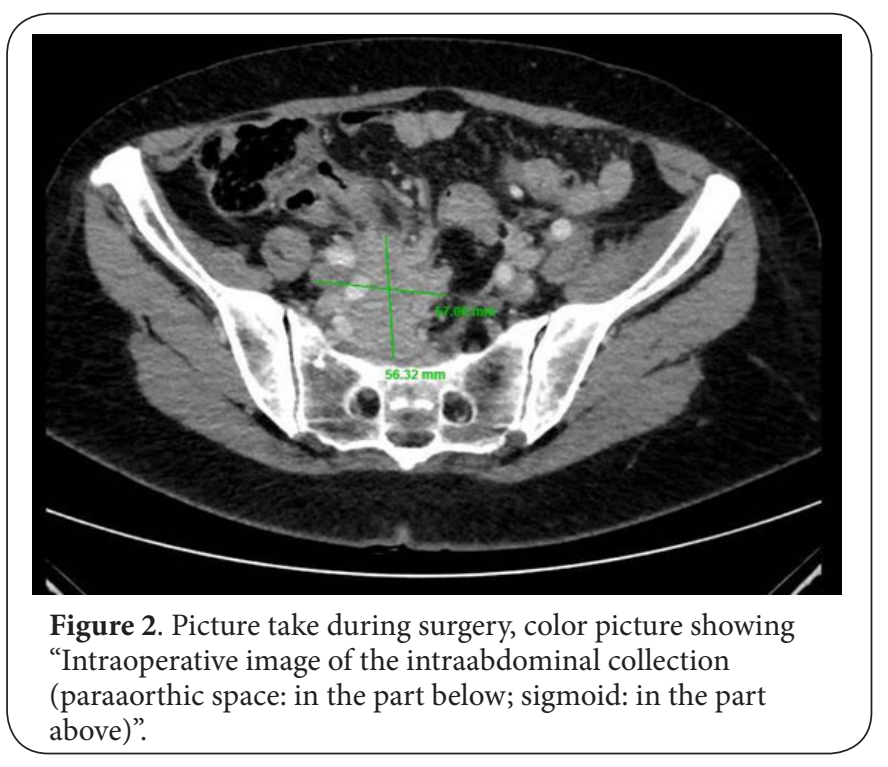

Postoperative recovery was regular, and antibiotic treatment was start (3 $\mathrm{g}$ dose/die of amoxicillin clavulanate) before discharge.

CT scan was performed three months after and it revealed regression of the mass and diverticulosis of the sigma (Figure 4), confirmed at contrast colography, in absence of signs of fistulisation.

\section{Discussion}

Actinomycosis is an indolent, progressive suppurative infection disease caused by Actinomyces species. Actinomyces are Gram-positive non-sporing, filamentous, anaerobic or microaerophilic bacteria. In human several Actinomyces (A.) species could be pathogenic: A. naeslundii, A. odontomlyticus, A. viscosus, A. meyeri, A. gerencseriae, A. bovis, but the most common one is $A$. israelii $[5,3]$. These bacteria normally colonize the oral cavity, upper gastrointestinal tract, and female urogenital tract. The incidence of the infection is 1:300000. These 


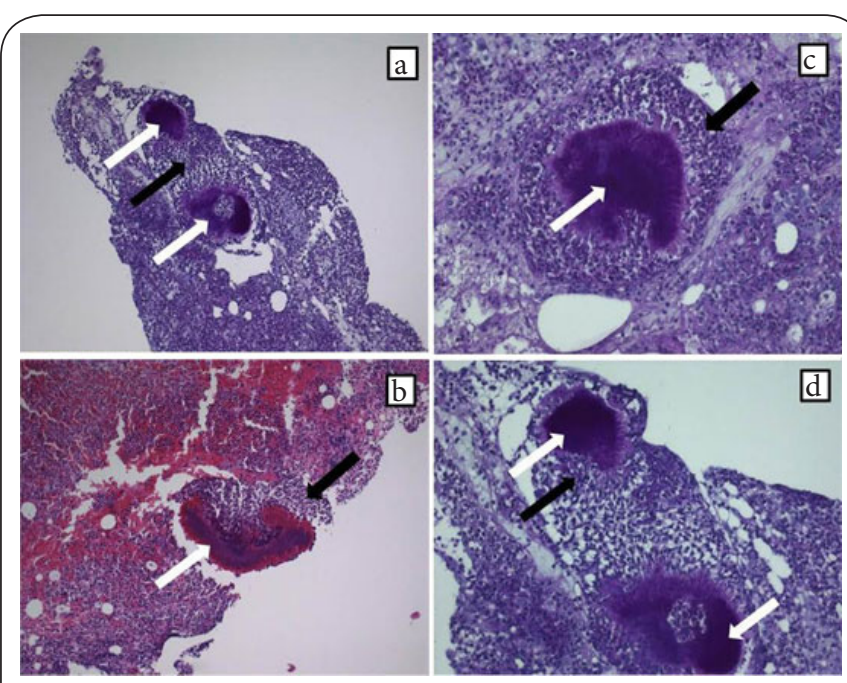

Figure 3. Actinomyces hyphae (white arrow) and inflammatory reaction (lymphocytes and macrophages black arrow) at definitive histopathological examination from surgical biopsy. (a) PAS 10X (b) EE 10X (c) PAS 40X (d) PAS 20X.

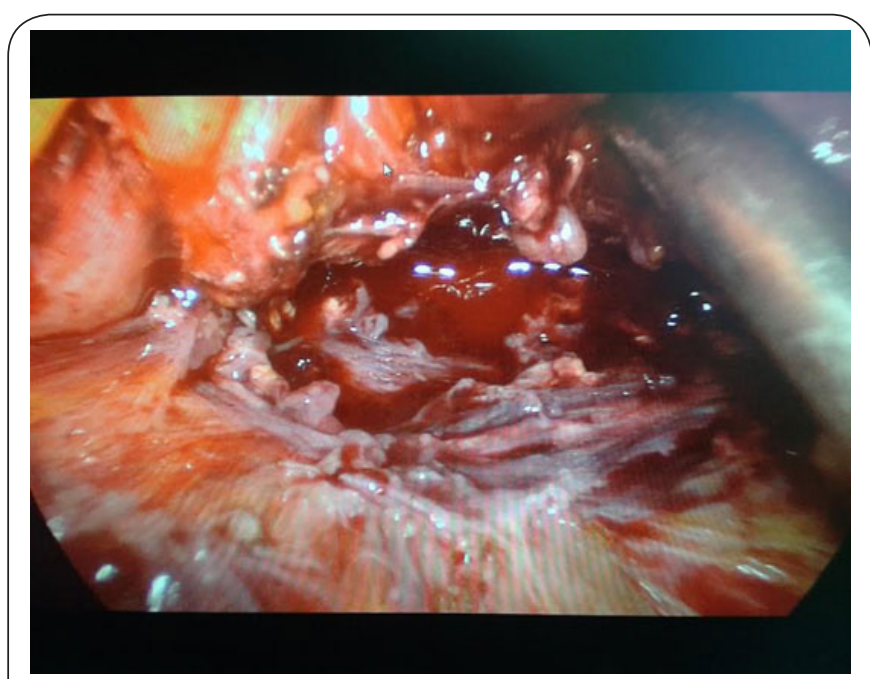

Figure 4. CT image with the small mass, currently positioned showing "Reduction of the pelvic mass near the right iliac vessels and right ureter, in the control CT scan at 3 months".

organisms are considered as opportunistic pathogens, and is more frequent in males, in midlife, in tropical world area $[1,2]$. In Western countries oral infection has decreased with better oral hygiene, but abdominal and genital actinomycosis are increase with the usage of IUD (8-20\% of women who have IUD for more than 2 years) [1-4].

Actinomycosis occurs most frequently in the cervical-facial (50-60\%), thoracic (15-30\%), abdominal (20\%) regions, and central nervous system (2-3\%) [3,4]. Sporadically also genitourinary involvement can occur with renal or perirenal masses [20]. Thoracic disease could result from a direct extension into the mediastinum from a cervical-facial infection, or as trans- diaphragmatic or retroperitoneal spread from the abdomen. Rarely also hematogenous spread to the lung is described [2]. Instead, the intra-abdominal actinomycosis presents often an abdominopelvic form. This form usually occurs after the disruption of the intestinal integrity (commonly appendectomy, perforated bowel, diverticulitis, surgery to the gastrointestinal tract, endoscopic procedures, or trauma), but sometimes no cause is identified $[3,6]$. In light of the low-growing and the indolent nature of the infection, the diagnosis can occur after months, or years. The spread is typically around the connective and fascial tissues [3]. The mucosal invasion is rarely present and endoscopic procedures do not identified any alteration [3-5]. Usually limphnodes are not involved in actinomycosis, and there is not a spread into the peritoneal cavity [2].

The main issue related to actinomycosis in western geographic areas is related to the difficult diagnosis (only in the $17 \%$ of cases the diagnosis is preoperative) $[3,7,8]$. Clinical features and imaging reports often mimic malignant lesions, inflammatory diseases, tuberculosis, fungal infection, acute necrotizing pancreatitis, endometriosis [3-5,7,9]. The most frequent presenting features, as in our case, are abdominal pain, weight loss, asthenia, even associated with abnormal vaginal bleeding or discharge in case of IUD usage. The bacterium is usually unable to cross the mucosal barrier, except that in late stages, associated with tissue injury and disrupted mucosa [3-5]. Usually no tumor markers are positive, and only a mild leukocytosis and fiver can be present [4].

About the histopathological point of view, the pathogens produce a characteristic granulomatous inflammatory response, with pus production and abscess formation, followed by necrosis and extensive, reactive fibrosis. When the diagnosis is suspected, confirmation can be obtained with FNA or core biopsy, performed with radiological guide or during surgical exploration [10]. Unfortunately, authors report highly variable rates (1-50\%) of isolation of $A$. species from the histological material $[3,5]$. In our case we found 3 different biopsies results in each bioptic sample, but all showing the presence of acute and chronic inflammatory cells (eosinophilis, histiocytes) and the Actinomyces hyphae (Figure 3 ) that were compatible with a framework of actinomycosis. In the literature was also reported as common finding of actinomycosis the "sulfur granules", stain Gram-positive with a mycelium-like structure, can help a definitive diagnosis (positive at PAS and Grocott colorations). These granules however can be present also in case of nocardiosis, streptomycosis, chronomycosis, eumycetomam botrymycosis [3-5,9]. However, this type of diagnosis can be hampered by previous antibiotic assumption. In order to increase the diagnostic capability is necessary to perform microbiological and histological samples before antibiotic therapy [11].

Radiological techniques allows to the diagnosis of an actinomycotic mass. Frequently, the apparent aggressive nature showed by the CT scan or Magnetic resonance image (MRI) images might lead to suspect malignant pathology. In-Jae 
Montori et al. Emergency Medicine and Health Care 2015,

http://www.hoajonline.com/journals/pdf/2052-6229-3-2.pdf

doi: 10.7243/2052-6229-3-2

Lee [19] describes the principal radiological aspects of abdominal actinomycosis. Each radiological finding can mimic abdominopelvic neoplasia; for this reason is important a correct differential diagnosis is fundamental. Commonly CT shows a solid mass with focal low-attenuation areas, and less frequently cystic mass with thickened wall [5]. CT pulmonary images usually appear as segmental airspace area containing necrotic low-attenuation areas with peripheral enhancement. Pleural involvement and the development of small abscesses can be present. In case of intra-abdominal actinomycosis the mass is surrounded by prominent inflammatory infiltration (solid tissue with soft tissue around), that can show strong enhancement after contrast administration $[3,7]$.

MRI can help in diagnoses, but has a low specificity: low signal intensity on T2-weighted sequences might be helpful to support this diagnosis $[3,5]$. In recent years the use of nuclear medicine to diagnose infectious and inflammatory disease is increasing. The accumulation of 18-FDG in PET is based on the high uptake of glucose in activated granulocytes [12]. Some authors show that PET is highly sensitive but not specific for actinomycosis infection, and can be interesting to evaluate the effectiveness of the antibiotic therapy [13]. Another radiological technique with an important role in the diagnostic of this infection is the Gallium-67-citrate scintigraphy [20]. This scintigraphy exhibits an increase uptake of radioactivity in infected foci.

Actinomycosis treatment is based on high doses of antibiotics, such as penicillin for 6-12 months [14]. Actually the approach changes with the site of infection, the severity of disease and the patient's response to treatment. In any case, patients must be monitored to evaluate clinical and radiological progress until the resolution of the infection.

Standard treatment is based on intravenous penicillin $G$ over 2-6 weeks, followed by oral penicillin $V$ ( $2-4 \mathrm{gr} /$ day) for 6-12 months [14,15]. The risk of developing penicillin, resistance is very low [14]. In pregnant women erythromycin can be safe, and in patients who are allergic to penicillin doxycycline, minocycline, clindamycin and erythromycin are suitable [14]. In intra-abdominal infection combination with amoxicillin and clavulanic acid with metronidazole, or clindamycin, can be used in case of anaerobes. However literature show an increased rate of recurrence after antibiotic therapy without simultaneous surgical resection of the infected areas [5].

The role of surgery in actinomycosis is secondary to the antibiotics treatment. Indications for surgical treatment are: extensive necrotic tissue, large abscesses or empyemas that cannot be drain, in case of compressive masses, to exclude a malignant pathology, or in patients that don't respond to medical treatment. In very compromised patients must be carefully assessed the risk-benefit due to a surgical intervetion. A short-term antibiotic treatment can be proposed after debulking surgery $[15,16]$. Particularly to define a diagnosis laparoscopy approach can be used, but is not safe in case of extensive infection [16].

\section{Conclusions}

Intra-abdominal actinomycosis is a severe infection that must be taken into account by surgeons. This infection can occur not only in case of IUD usage, but also in other common intestinal pathologies. Early diagnosis is important to avoid the morbidity associated with an extensive surgical resection. Surgical biopsy is valuable as a definitive diagnosis when the diagnosis with non-invasive technique is not nullifying. Antibiotic therapy is the standard treatment and surgery can help to optimize medical approach removing necrotic tissue and persistent sinuses.

\section{Competing interests}

The authors declare that they have no competing interests.

\section{Authors' contribution}

\begin{tabular}{|l|l|l|l|l|l|l|l|l|l|l|l|l|l|l|}
\hline $\begin{array}{l}\text { Authors' } \\
\text { contributions }\end{array}$ & GM & AA & GM & PF & EP & FC & RM & DP & AT & FF & AG & LB & NP & LA \\
\hline $\begin{array}{l}\text { Research } \\
\text { concept and } \\
\text { design }\end{array}$ & $\checkmark$ & $\checkmark$ & -- & -- & $\checkmark$ & -- & -- & -- & -- & -- & -- & -- & -- & $\checkmark$ \\
\hline $\begin{array}{l}\text { Collection } \\
\text { and/or } \\
\text { assembly of } \\
\text { data }\end{array}$ & $\checkmark$ & $\checkmark$ & $\checkmark$ & -- & -- & -- & -- & -- & -- & -- & -- & -- & -- & -- \\
\hline $\begin{array}{l}\text { Data } \\
\text { analysis and } \\
\text { interpretation }\end{array}$ & -- & -- & -- & -- & $\checkmark$ & -- & -- & -- & $\checkmark$ & $\checkmark$ & $\checkmark$ & -- & -- & - \\
\hline $\begin{array}{l}\text { Writing the } \\
\text { article }\end{array}$ & $\checkmark$ & $\checkmark$ & $\checkmark$ & -- & -- & -- & -- & -- & -- & -- & -- & -- & -- & - \\
\hline $\begin{array}{l}\text { Critical } \\
\text { revision of the } \\
\text { article }\end{array}$ & -- & -- & -- & -- & $\checkmark$ & $\checkmark$ & $\checkmark$ & $\checkmark$ & -- & -- & -- & -- & - & $\checkmark$ \\
\hline $\begin{array}{l}\text { Final approval } \\
\text { of article }\end{array}$ & $\checkmark$ & $\checkmark$ & $\checkmark$ & $\checkmark$ & $\checkmark$ & $\checkmark$ & $\checkmark$ & $\checkmark$ & $\checkmark$ & $\checkmark$ & $\checkmark$ & $\checkmark$ & $\checkmark$ & $\checkmark$ \\
\hline
\end{tabular}

\section{Acknowledgement}

The authors would like to thank to Arianna Heyer for proofreading the manuscript.

\section{Publication history}

EIC: Joseph Varon, University of Texas Medical Branch, USA. Received: 16-Jan-2015 Final Revised: 12-Apr-2015

Accepted: 15-Apr-2015 Published: 23-Apr-2015

\section{References}

1. Berardi RS. Abdominal actinomycosis. Surg Gynecol Obstet. 1979; 149:257-66. | Article | PubMed

2. Brown JR. Human actinomycosis. A study of 181 subjects. Hum Pathol. 1973; 4:319-30. | Article | PubMed

3. Heo SH, Shin SS, Kim JW, Lim HS, Seon HJ, Jung SI, Jeong YY and Kang HK. Imaging of actinomycosis in various organs: a comprehensive review. Radiographics. 2014; 34:19-33. I Article I PubMed

4. Ferri F. F. Ferri's Clinical Advisor. Expert Consult. Ed. Elsevier. 2013; 3536.

5. Wagenlehner FM, Mohren B, Naber KG and Mannl HF. Abdominal actinomycosis. Clin Microbiol Infect. 2003; 9:881-5. | Article | PubMed

6. Yeguez JF, Martinez SA, Sands LR and Hellinger MD. Pelvic actinomycosis presenting as malignant large bowel obstruction: a case report and a review of the literature. Am Surg. 2000; 66:85-90. | Article | PubMed

7. Bae JH, Song R, Lee A, Park JS and Kim MR. Computed tomography for the preoperative diagnosis of pelvic actinomycosis. J Obstet Gynaecol Res. 2011; 37:300-4. | Article | PubMed

8. Nissi R, Blanco Sequeiros RB, Lappi-Blanco E, Karjula H and Talvensaari- 
Mattila A. Large bowel obstruction in a young woman simulating a malignant neoplasm: a case report of actinomyces infection. Case Rep Obstet Gynecol. 2013; 2013:756768. | Article I PubMed Abstract | PubMed Full Text

9. Hamid D, Baldauf JJ, Cuenin C and Ritter J. Treatment strategy for pelvic actinomycosis: case report and review of the literature. Eur J Obstet Gynecol Reprod Biol. 2000; 89:197-200. | Article | PubMed

10. Lee YC, Min D, Holcomb K, Buhl A, DiMaio T and Abulafia O. Computed tomography guided core needle biopsy diagnosis of pelvic actinomycosis. Gynecol Oncol. 2000; 79:318-23. | Article I PubMed

11. Russo TA. Agents of actinomycosis. In: Mandell GL, et al., editors. Principles and Practice of Infectious Diseases. New York: Churchill Livingstone. 2000; 2645-54.

12. Glaudemans AW, de Vries EF, Galli F, Dierckx RA, Slart RH and Signore A. The use of (18)F-FDG-PET/CT for diagnosis and treatment monitoring of inflammatory and infectious diseases. Clin Dev Immunol. 2013; 2013:623036. | Article | PubMed Abstract | PubMed Full Text

13. Singla S, Singh H, Mukherjee A, Karunanithi S, Bal C and Kumar R. Cervical and thoracic actinomycosis on (18)F-FDG PET/CT. Clin NuCl Med. 2014; 39:623-4. | Article | PubMed

14. Wong VK, Turmezei TD and Weston VC. Actinomycosis. BMJ. 2011; 343:d6099. | Article | PubMed

15. Trutnovsky G, Tamussino K and Reich O. Short-term antibiotic treatment of pelvic actinomycosis. Int J Gynaecol Obstet. 2008; 101:203-4. I Article I PubMed

16. Acquaro P, Tagliabue F, Confalonieri G, Faccioli P and Costa M. Abdominal wall actinomycosis simulating a malignant neoplasm: Case report and review of the literature. World J Gastrointest Surg. 2010; 2:247-50. I Article I PubMed Abstract | PubMed Full Text

17. Huang CJ, Huang TJ and Hsieh JS. Pseudo-colonic carcinoma caused by abdominal actinomycosis: report of two cases. Int J Colorectal Dis. 2004; 19:283-6. | Article | PubMed

18. Koren R, Dekel Y, Ramadan E, Veltman V and Dreznik Z. Periappendiceal actinomycosis mimicking malignancy report of a case. Pathol Res Pract. 2002; 198:441-3. | Article | PubMed

19. Lee IJ, Ha HK, Park CM, Kim JK, Kim JH, Kim TK, Kim JC, Cho KS and Auh $\mathrm{YH}$. Abdominopelvic actinomycosis involving the gastrointestinal tract: CT features. Radiology. 2001; 220:76-80. | Article I PubMed

20. Lin CD, Tai HC, Wang CC, Chung-Tai Yu CT, Chang SJ, Hsieh CH and Yang SSD. Renal actinomycosis: an unusual cause of renal abscess. Urological Science. 2012; 23:129-132. | Article

\section{Citation:}

Montori G, Allegri A, Merigo G, Poiasina P, Coccolini F, Manfredi R, Piazzalunga D, Tebaldi A, Filippin F, Gianatti A, Baiocchi L, Portolani N and Ansaloni L. Intra-abdominal actinomycosis, the great mime: case report and literature review. Emerg Med Health Care. 2015; 3:2. http://dx.doi.org/10.7243/2052-6229-3-2 